NAGy, GÁBOR DÁNIEl PhD, HABIL

ngd@dartke.eu

associate professor (University of Szeged, Faculty of Arts, Institute of Social Sciences, Szeged)

\title{
A survey research among employees at a Chinese Company
}

\author{
A Case Study of Incentive Effectiveness \\ on Employee Performance at Suning Corporation
}

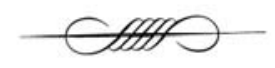

\begin{abstract}
Incentives form an indispensable part in the operations of a company regardless its social and cultural context. In this article I have reviewed different types of incentive schemes. I have conducted a case study with secondary analysis of data about Suning corporation, which is a Chinese retail store network. The research observed that coming up with an executive incentive framework increases the loyalty of the staff at the workplace. The methodology for researching on Suning gives a rational base of the whole incentive process. The description is also dependent on the scientific basis and interpretations based on the logical concepts identified. The principles are related to the tools used in the research as well as the techniques that could be applied in the study. The research reports on the most critical or appropriate methods of study that have been selected to carry out the research.
\end{abstract}

\section{KEYWORDS}

Human resource management, incentives, social capital, incentive shcemes

DOI 10.14232/belv.2019.4.16 https://doi.org/10.14232/belv.2019.4.16

Cikkre való hivatkozás / How to cite this article: Nagy, Gábor Dániel (2019): A survey research among employees at a Chinese Company. A Case Study of Incentive Effectiveness on Employee Performance at Suning Corporation. Belvedere Meridionale vol. 31. no. 4. 221-232. pp.

ISSN 1419-0222 (print)

ISSN 2064-5929 (online, pdf)

(Creative Commons) Nevezd meg! - Így add tovább! 4.0 (CC BY-SA 4.0)

(Creative Commons) Attribution-ShareAlike 4.0 International (CC BY-SA 4.0)

www.belvedere-meridionale.hu 


\section{INTRODUCTION}

Suning was incorporated in 1990 of which it grew to become a leader in China's retail sector. The company has a wide range of commodities including consumer electronics, household goods, virtual products, books, daily necessities, and general merchandise. The company was then listed in Shenzhen Stock Exchange in July 2007 after being accredited by the stock market due to its performance. The management attached much significance to the company's after sales department as a leading retailer. The firm presently has close to 5000 professionals working as service personnel what have so far contributed to business success. When compared with other multinational firms like Wal-Mart and Tesco, the company's aftersales department is found to have a big room for improvement still. Incentives form an indispensable part in the operations of Suning regardless of the marketplace. In this literature review, we have secured different sections of incentive schemes. The research observed that coming up with an executive incentive framework increases the loyalty of the staff at the workplace.

\section{BACKGROUND}

A company has several elements giving it opportunities to improve its working environment. Among the features include creating the right name as a company that values its workers. With Suning Commerce as the major research project, the paper analyses the incentive plan for the commerce together with the effects of implementation. The paper analyses the causes of failure of the incentive plan within suning among them being fixed executive price which is not to be adjusted based on the changes of the stock price, high assessment criterion within the strategy transition period and the correlation between the stock price as well as the incentive plan an how it needs to be implemented. Workers being part of the stakeholders also need to be dealt with effectively. The satisfaction of the workers is dependent on the level of motivation which the company needs to consider a priority. In case it happens that the workers are satisfied and highly motivated, the company stands to gain from the outcome. The close connection of the incentive items in based on the company's performance indicates that there is a consistent interest between the management and the company which helps in reducing the stock performance. The relationship helps sunings to reduce the supervision cost, agent risk and to a given extent, retain the talents. The incentive theory states that the higher the incentive level, the more productive the management will be in improving the work presentation thereby leading to a high level of workforce satisfaction. The company through the introduction of talent show and management can help in coming up with a better incentive scheme. However, in such systems, the company has to consider the relevance of the talent and management criteria to the business (RICHARD 2001). The objective of the study is therefore to identify the importance of the incentive scheme, to assess the ideal system of Suning Holdings, Understanding the effectiveness of the incentive system and to provide various recommendations on how to improve the methods for an incentive for the company. The research questions used in the study therefore include:

1. What is the ideal system for an incentive?

2. How effective is the incentive scheme for Sunning?

3. What is the importance of the incentive system?

4. What are the main methods of planning and assessing the incentive process? 


\section{Problem}

Suning in 2010 issued a stock option incentive plan to its workers of which there were 248 backbones who benefited including the company president, vice president, core managers, chain store keepers and other workers. The director and the store keepers however received more of the stock options. The rule of the motivation system needs to be planned in a manner that the business never feels that it is overburdened. The incentive system in Suning is meant to ascertain that there is an actual cost increase to the market if it is not designed expertly. There is a need for maintenance cost by the time the company plans for an incentive system. Suning's management had to allocate adequate funds within the incentive system. The funds were to help in the corroborating and also supporting the incentive requirements within the company. Sunings incentive system was to enable the company create a positive working atmosphere which allows the business to share its wealth with the workers as well as influencing their mindset which creates a confident psychosomatic level. The motivational theories have earlier recommended that same outcomes and perspectives for the bonus system. The business needs to provide a proper remuneration system supported by the management which also has to include the incentive framework. The presence of competition within the private sector has made Suning incentive system to remain popular among most business entities. Suning commerce provides incentives to the workers through a variety of ways. Among the methods is where the company decides to fix particular amounts after the sales level has been attained. A sound incentive system needs to justify the efforts made by the employee in production. The system was earlier used to attract the workers and also inspire them to endure improving their presentation. Suning has also dedicated a provision of incentives to their workers as they continue to understand the actual company values. In the current business environment, provision of proper incentives has become part of company ethics based on how it is practiced. The company may, however, face different problems as it tries to formulate an ideal and valuable design for the incentives that will ensure that there are mutual benefits to both the company and the workers. The employee's performance assessment acts as one of the significant factors used to determine the incentive system in Sunings. The formulation of the incentive system could, therefore, face challenges based on how it is manipulated on the performance criteria (FUNK 2012). The incentive criteria could give rise to corruption in the company due to the unethical practices by the managers not fulfilling their responsibilities and take advantage of the system to reward their loyal subjects. The principle of the incentive system, however, suggests that the function of each is diverse towards the making of the incentive system and in ensuring that it remains efficient. Within the report, much priority has been to understand the convenience and the different dimensions used for the incentive systems. Much deliberation has also been allocated to planning the paramount motivation system that will enable the business to fulfill the worker's expectations.

The primary significance of the research is that it is intended to deliver an effective outcome concerning improving the systems for incentives within the related corporations. From the research report, the best reward system can be identified in regards to the retail market in which Suning operates. Further, the limitations that may be faced while trying to decide on the best scheme within the customer service department can be resolved thereby making the research more significant in a different section.

The methodology for researching on Suning gives a rational base of the whole incentive process. The description is also dependent on the scientific basis and interpretations based on the logical 
concepts identified. The principles are related to the tools used in the research as well as the techniques that could be applied in the study. The research reports on the most critical or appropriate methods of study that have been selected to carry out the research.

The perspective for the research shows that the study on Suning incentive aims towards the subject matter which is the incentive scheme. The research also offers different scopes of knowledge to help the understanding the topic better. In regards to the current study, two types of philosophies can be applied. The views include interpretive research philosophy whereas the other is positivism research philosophy. Within the positivism viewpoint, the study emphases on the general facts and figures which remain constant globally regardless of the economic conditions (WALLIMAN 2017). There is no possibility of changing into the opinion and viewpoint irrespective of the changing conditions. To get different beliefs, the study can be dependent on the interpretive philosophy. Indulgent in the educational research is therefore essential since it gives the reader a wide range of awareness and intellect in getting deeper into the subject matter. Interpretation of Suning incentives enables the reader to understand and analyze the different possibilities available in the surrounding environment. The most relevant research philosophy for the study is mixed research since the private corporations operate in a vibrant setting of which there is a significant focus on evaluating the changing climate. There also exist more requirements to help in focusing and assessing an appropriate motivation plan that is dependent on diverse situations. The thoughts of different personalities could be evaluated to make a better incentive plan. Therefore, educational research is applied to facilitate the success of the study. The study will stresses on the point of knowledge on incentives in Suning's that needs to be developed based on the empirical facts of observation as well as revealing the actual summary of the research based on the fundamental principles.

The approach used in analysing Suning incentive involves techniques that have been carefully selected and planned. The method is building on the analysis of the secondary information that had earlier been collected. The strategies that can be applied within the study include deductive and inductive research (WALLIMAN 2017). The inductive method of analysis is one in which the researcher gets first-hand information on the event which helps in concluding. The inductive approach facilitates the basis for proposing a new concept. Deductive criteria are one in which the person performing the study is committed to checking the relevance of the situation, concept of the statement. In a deductive approach, the researcher is confined to specific limitations of researching within a given area. The total focus needs to be diverted to the inductive approach to enable the research team to come up with an efficient incentive plan that can be adopted by Suning holdings. With the assistance of inductive criteria, it is possible to spot the best internal working setting having a background incentive plan.

The methodologies that were considered in the study are two types of research techniques; they comprise of qualitative and quantitative methods. The two ways are important in improving the reported value. The nature of the data from the qualitative report indicates that there is no application of the statistical tools in performing the analysis. The qualitative data subjective and the information it depends on is always lengthy. The quantitative research, on the other hand, is related to the adaptation of the statistical tools such there is the use of different soft wares to measure the information collected (PATTEN-NEWHART 2017). The nature of the study, however, calls for a quantitative approach where the information used is objective, and the analytical tools need to be applied in the most appropriate manner. 
Through the use of a questionnaire's secondary analysis, a survey involving the collection of data on the incentive system for Suning Company via paper questionnaire and email was used. The number of respondents for the study based on the intended population was 400 . However, from the data sampled, there was only 300 valid feedback from the respondents who were finished within the designated timeline. There were no survey data intended to be released to the third parties to help in protecting the privacy of the whole research process (PATTEN-NEWHART 2017).

The data collected was from both primary and secondary sources for materials related to Suning. The primary sources included the use of questionnaire (secondary analysis) whereas the secondary sources included the published material. Based on the literature review, it is evident that six dimensions affect the satisfaction of employees. The aspects can be illustrated as shown in the figure below:

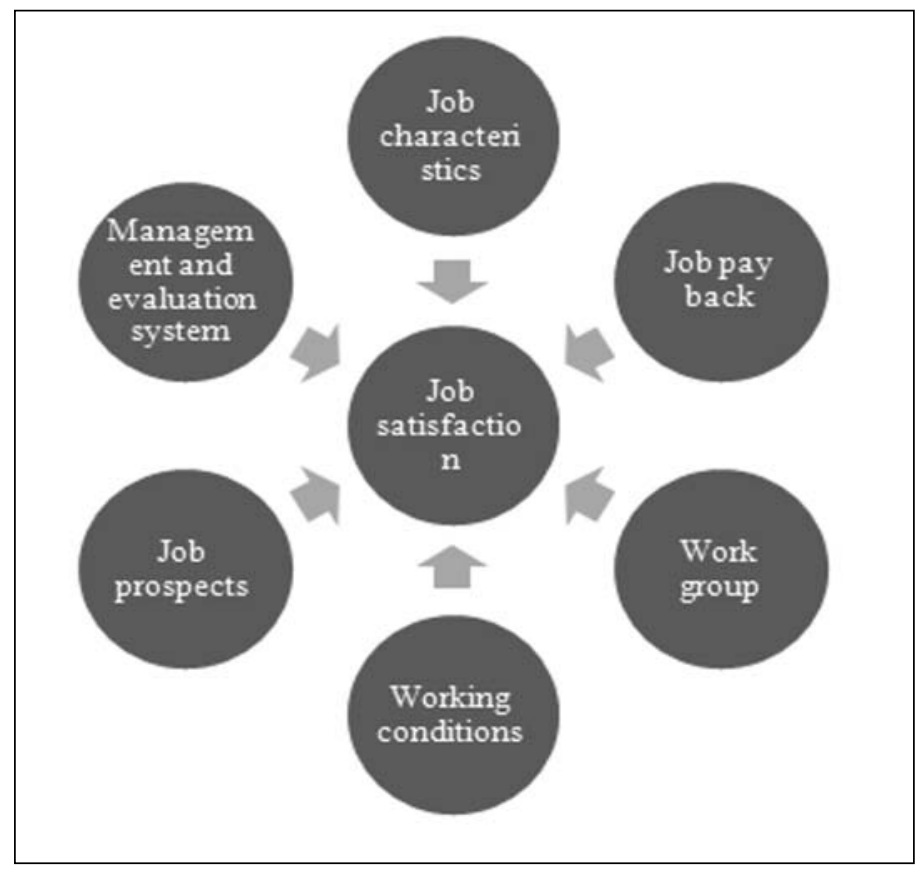

FIGURE 1 Illustrating the model for six dimensions

The design for the questionnaire was originally based on the six hypothetical models of incentive. The first part of performing an empirical analysis is to carry out scientific, statistical analysis to help in understanding the distribution of data based on analysis of Suning. After getting to know the distribution, what followed was understanding the validity of the questionnaire used in data collection in Suning. Conducting a regression analysis on the survey helps in finding out the factors that affect the worker's satisfaction.

The analysis design attracts the questionnaire for operative fulfilment which is extremely embattled due to the reliability and validity. The information is combined with the expansion prominence together with the features of the system adopted by Suning's customer service sector. 
The regression analysis performed helps in working out the key issues that influence the customer and employee satisfaction level from the customer service department within Suning Holdings.

To ensure that the study is reliable and valid, collection of data was dependent on the methods as well as the procedure used while sampling the data. The sample size of 400 used is enough to get the relevant information based on the given feedback. The data collected enabled the study to attain the expected conclusion. To ensure that the results gathered are reliable, it is essential to verify that the information collected is from Suning's workforce.

To carry out a valid and authentic report, there is need to have an ethically compliant team that aligns to the requirements of the research. The major ethical issue related to the study of Suning's incentive is having to plagiarize from the secondary data instead of carrying out original research and probably make a comparison. The resources for gathering the data were cited which the online sources used were proved to be having trusted information as noted by the researchers. The data gathered also had to be entered the way it was received to avoid manipulation of the information. The research also tried to be eco-friendly by distributing the questionnaires through email thereby reducing the hustle in data collection.

The research found out that an increase in the wage in Suning has the highest mean whereas the workload possessed the lowest mean. The other variables like the wage income, cultural atmosphere and the nature of the job that one does, bonus, job challenges, interpersonal relationships all play an essential role in determining the satisfaction of a worker. The salary income is significantly correlated with the satisfaction followed by the environment that one is exposed to in Suning.

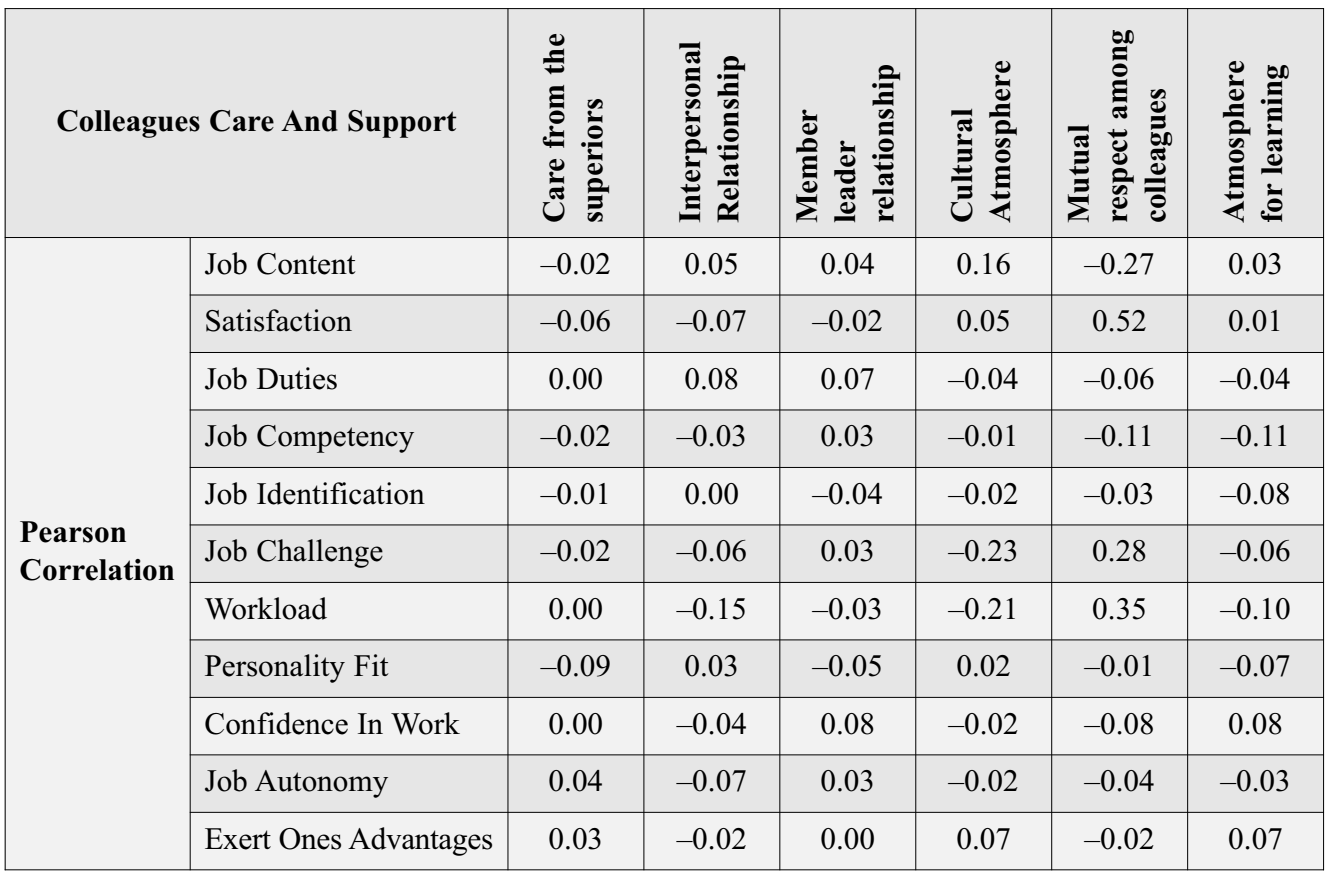

TABLE 1 Showing cross correlation 


\section{Discussion}

In Suning, the incentive feature has gained much prominence in the current past as an aspect of human resource administration as well as in making the workers satisfied and happy. According to MARSCHKE and HEINRICH (2010), the system can be defined as that which motivates the workers to improve their performance on some set of actions and also to enable them to complete the different functions that will allow them to accomplish the company set targets and goals. The human resources act as one of the most valuable company assets that the company can possess since they provide precedence on the steps taken to satisfy the needs to the required extent. The incentive system, therefore, has a vital role to play within the company. The business needs to pay reasonable amounts of incentives to the workers to increase the motivation level and also increase their performance which will increase the personal loyalty and commitment to the organization. It thus implies that in case the company wants to sustain its market for a prolonged duration, and also fulfil the corporate goals, then the best method to use it the incentive system. The system is, therefore, a success factor in the company which can be relied upon. Employees feel more motivated when they are appreciated in monetary terms of which when they are provided with incentives, then they feel like they are part of the company. Therefore, the human resources department needs to develop a proper incentive system to help it in addressing the required skills and attributes needed for the production sector. In this context, the incentive system can be regarded as a procedure used to recognize the workers' efforts to help in fulfilling the company goals as well as the set mission and vision. Whenever a company is not in a position to develop a better remuneration package in terms of incentive, then it will not be in a position to sustain its place in the market for a prolonged period.

The system could also be defined as an approach based on the workers' performance that needs proper assessment. It is therefore through the incentives as noted by MARTIMORT (2009) that the Suning's human resource department can motivate the workers thereby ensuring that the performance is maintained as the organization desires. When the set goals are achieved, then the company will be in a position to ease comfort thereby allowing it to motivate the workers. They further suggest that the incentive system is not an element of production thereby making it possible for the company to survive without the arrangement. In other aspects, the incentive system can be in non-monetary terms. Companies, therefore, need to come up with a scheme that identifies the workers who can be motivated in monetary terms and those who need the nonmonetary benefits like through promotions. Need for the incentives systems in the company: In incentive scheme is an essential form of the company's business operations since, in essence, it has a significant influence on business operations. The incentive scheme also plays a role in business existence. The significance of the inventory systems has over time grown by more significant margins thereby doing businesses regardless of the operating market segment to pay attention towards the system. The business success is also dependent on the level of the employee motivation thereby making incentive an effective way of ensuring business success. The system is thus the best method of encouraging the workforce thereby increasing the level of loyalty to the company. The scheme also motivates the workers to push and provide themselves with a challenge which in turn results in higher productivity which in the long run translates to increased earnings to the business. The employees work while having in mind that the better the performance, the more the pay which drives them to continue working and giving quality output for a given period (Li 2016). 
The significance of incentives can also be improved by promoting working as a team among the employees. Teamwork is essential for the company's success since it is mostly dependent on the level of collaboration. Through the incorporation of different employee incentive programs, the company management is in a position to give the workers motivation to work in other teams and also make a contribution to attaining the organizational goals and objectives. Provision of group incentives can also help in motivating presentation and nurturing the organization within the company. It also implies that the workers will have to provide their task inputs at hand thereby creating a group founded setting within the workplace. MASON and WATTS (2010) observe that teamwork helps the business to increase effective performance thus maintaining the brand image of the firm. In other instances, peer pressure can act as a motivation for excellent individual performance. Teamwork makes the process of operating in the market much more straightforward and also more effective since the company mission, vision, goals, and objectives are achieved in the required time.

Incentives also act as a morale booster to the workers thereby increasing the workers' job satisfaction level. The business needs to take steps necessary to help it in boosting the workers' morale thus ensuring that they remain committed to the increasing production and attaining the company goals. There is a straight and constructive correlation between the employees work efforts and the organizations' revenue. Whenever there is high morale among the workers, the company's turnover is reduced which also will have an impact on the business market performance, operations, and its existence (LEWIS-SMOKE 2017). The cost of signing and that of drilling the new workers is also reduced immensely which in turn may help the business to function better due to the reduction of the expenses and in the long run, attain the intended objectives.

The programs are also of importance to the company since they immensely affect the business delivery system and the service quality. When the workers are given the right incentive system, they are in a position to corporate at work thereby increasing the quality of products and service as well as the delivery services. The situation necessitates the need to offer the workers a better compensation scheme which will motivate then work towards the attainment of the business goals.

An ideal incentive system: The company needs to have a proper incentive plan that will help in improving the general employee performance within the workplace. Several motivation systems and methods have been established by different corporations to assist in achieving employee satisfaction level. Among the schemes include group incentive schemes or special incentives. The business, therefore, needs to compare functions with the available incentives then select the one that best suits its performance. The opportunities will help the company to emphasize the features thereby extending its existence by a significant margin. The incentive plan that can be recommended in such a scenario is the individual scheme which has differential piece rate plans, Gantt Task, and Bonus Plan; Emerson Efficiency Plan, Rowan Premium Plan; and Halsey Premium Plan (Degerstrom 2018). The piece rate plan is the best out of all the projects since it has an effective incentive scheme. Piece rate plan was developed by F. W. Taylor who was the father of scientific administration which is still applicable to the present organisation operations. Piece rate plan is beneficial to the occupational initiatives mainly since it mostly emphases on the employees' output. Within the system, the business has to follow the notion of two-piece work rates whereby one is has a higher price for determining the employee wage rate for the workforce attaining the company standards whereas the other is for the ones who are not in a position to achieve the set benchmark. It makes it possible to draw a clear distinction between the workers who have contributed towards the company goals and those who could not manage to attain the standards. 
The differentiation among the workers can help in motivating the workers who do not reach the set goals and benchmarks to identify the areas and sections of improvement that will enable them to catch up with the rest. The approach is, but it eventually helps the organization in enhancing the employees' performance. When the system is applied in the right manner, it may help the business to attain positive results in return apart from prolonging its market existence. The company may also be in a position to achieve the set goals and objectives since the production methods have been made simpler. It is however not easy for the corporations in the service business to advance the work morals then put them into practice within the place of work since system becomes difficult to use after most of the workers attain the set standards which makes it unsustainable to the firm. The situation may make it difficult for the firm to survive in the market for a considerable period thereby making goal fulfillment a challenge. There are also no specific guidelines measuring the working standards in the firm making it challenging to the company to apply the incentive system. Other studies according to PEKKANEn et al. (2006) contrasts by suggesting that regardless of the sector one or industry may be operating in, determination of the standards is always an easy assignment. Pekkanen et al. support the research by providing examples that within the service industry like the hotels and restaurants, the rules of service is evident based on the time taken by a worker on a particular customer's table. Better performance in such a scenario, therefore, can be awarded to the employees who are in a position to deliver faster service to the customers whereas those who are slow are regarded to be performing poorly. Within the manufacturing environment, the companies' set benchmarks depending on the manufactured machinery parts within a given time frame. In case a workers productivity is high, then he is considered to be performing well and in a position to meet the company set standards. The employees conduct therefore needs to be measured and also evaluated through keeping in mind the different facets like the equipment's, raw materials available or the consumed time during production. An individual's performance, therefore, needs proper assessment in a holistic manner that would take into account the factors like to market forces.

In the group incentive system, the worker's performance is evaluated based on how effective they work as a team. Teamwork is one of the best methods of enhancing performance thereby helping the employees attain the organizational goals as they collaborate in the assignments given. However, according to BALLWIESER and et al. (2012), in a teamwork setting it becomes challenging to monitor and also assess the performances based on the individuals since there is no set manner to determine the individual performance. In such a way, it becomes challenging to reward group work to particular persons. The management may face difficulties in trying to assess the incentive scheme to be given to the workers based on such group work assignment.

There also exist other types of incentive systems like the co-partnership, profit sharing among others of which in profit sharing, the business shares the gains with the workers in the form of incentives. The method is significant since it encourages the workers to be loyal to the market and also at the workplace. Loyal staff always work towards attaining the company set objectives. According to BALLWIESER and et al. (2012), if the Suning distributes the gains earned over a given duration, it may eventually have decreased earnings. Stock option for the incetive started in 1950s but was adopted in China in 1980s. Such a scenario may influence the business flow of work within the operating environment since the company will have reduced financial resources thereby impacting the long term goals and objectives. However, profit share remains the best way to motivate the staff which increases their loyalty and determination at the workplace. The approach encourages the workers to give their best in terms of performance which in the long run benefits the company through more earnings and profits. 


\section{Limitation of the study}

The major limitation as collected from the research is secondary analysis of already existing data. Another limitation that the research could not take into account the knowledge on the interview situations to approach the employees and retrieving information from them (HANCOCK-ALGOZZINE 2017). The employees in Suning were not willing to share the data with the team thereby limiting data collection. Getting people with respect and conduct during the research was also a problem. The study was carried during Suning working hours thus making it a challenge to get the respondents since most of them were busy with the assigned responsibilities at work. Most of the respondents were from the company thereby making it a challenge to survey during the regular working hours.

\section{CONCLUSION}

The company's primary aim is to operate for the benefit of the stakeholders' including the employees. The workers play a significant role in handling and propelling the company operations. Therefore, satisfying the needs of the customers' needs to remain a primary goal of the business and it needs to be treated as an issue of priority. The incentive scheme is one of the significant motivation channels that the company has to factor. The incentive can be treated like a new figure that the company has to share with its workers. The bonus system helps in creating a positive relationship between the workers and the management. Therefore, the creation of a constructive and outstanding remuneration structure can help the company in delivering the performance from the workers thereby increasing the net returns. According to the theory of Herzberg, incentive theory needs to be one that provides proper remuneration to the employees.

There are specific issues that could be looked at by the organizations while detailing a perfect and gainful impetus plan. The evaluation of the performance of representatives is one of the significant issues that could be treated as a test to the motivator framework. The development of a motivating force framework could also face challenges related to controlling within the performance framework. It could likewise bring forth debasement and dishonest exercises if the chiefs are not satisfying their duties. In this manner, the standards of a motivation theory propose that the job of every single individual is massive in making the motivator framework viable and proficient. Incentives, therefore, have a role to play in the business progress thereby promoting the company to design a better method to help in boosting the system When a company intends to sustain its position within the market for a more extended period as it meets the corporate goals, then it needs not to look further than the incentives.

The incentive scheme is a good motivator for the employees that enables them to give themselves targets and goals related to productivity. The system acts as a morale booster whenever the production levels go down thereby justifying the need for having the scheme. When the morale is increased, then it is possible to have the employee's satisfaction level also increasing thereby increasing productivity. The system also serves as a way of ensuring that the company retains its productive employees. The workers will not have to search for employment elsewhere if the company rewards their efforts handsomely. Thorough applying interpretive research in the study, the company is in apposition of adopting the empirical thoughts realized from the fieldwork to help 
it in improving the working relations with the staff. The team concentrates more on the inductive method to assist in getting a viable solution for Suning Holdings. The approach makes it easier to observe the best way to operate in the external environment while having in mind the context of a bonus plan. The research was conducted in a quantitative approach where the study incorporated a piece of objective information. The collected data was both from secondary sources and primary sources thereby making it easy to analyse the outcome. The variables that were used for the study consisted of the wage income, wage increase, the content of the job, cultural atmosphere, the bonus, the challenges faced in the working environment, interpersonal relationship influence and the level of praise all of which play a part in guaranteeing that the staff gets motivated and also satisfied. It thus implies that motivation is not only through monetary benefit since there are also aspects of the non-monetary factor playing a part in the influence. The outcome of the study, therefore, aligns with Maslow's hierarchy theory. The theory suggests that it is not possible to motivate human beings from similar vigour since people have dissimilar desires. The incentive program to be designed in Suning holdings, therefore, should appear in a way that demonstrates both the fiscal and non-monetary aspects.

\section{Findings}

1. Suning Holdings needs to select from different incentive schemes highlighted like the company incentive plan, individual or even group incentive plan based on the set objectives.

2. The company should come up with a performance matrix tool that has to incorporate it in the remuneration scheme for the employee incentive structure. The project can be relevant to the company in avoiding conflicts in the reward system.

3. The incentive system should not be biased. It needs to be both monetary and non-monetary for all the staff to increase the level of morale.

4. Suning should also divert more of attention on the praise and commendation, cultural atmosphere, wage income, challenges experienced at the workplace, salary increase, and interpersonal relationship as it tries to come up with a new design for incentive.

5. The scheme needs to be purely dependent on work performance and not on the employee's position.

\section{REFERENCES}

BAllwiEser, W. et. al., (2012): Agency theory, information, and incentives. Springer Science \& Business Media.

Degerstrom, A. (2018): BRTOD. State of the Practice in the United States.

FunK, P. (2010): Social incentives and voter turnout: evidence from the Swiss mail ballot system. Journal of the European Economic Association vol. 8. no. 5. 1077-1103.

Hancock, D. R.,-Algozzine, B. (2016): Doing case study research: A practical guide for beginning researchers. Teachers College Press. 
LAFFOnt, J. J. - MARTIMORT, D. (2009): The theory of incentives: the principal-agent model. Princeton University Press.

LEWIS, B. D. - SMOKE, P. (2017): Intergovernmental fiscal transfers and local incentives and responses: the case of Indonesia. Fiscal Studies vol. 38. no. 1. 111-139.

LI, Q. (2016): Fiscal decentralization and tax incentives in the developing world. Review of International Political Economy vol. 23. no. 2. 232-260.

MASON, W. - WATTS, D. J. (2010): Financial incentives and the performance of crowds. ACM SigKDD Explorations Newsletter vol. 11. no. 2. 100-108.

PATtEn, M. L. - NEWHART, M. (2017): Understanding research methods: An overview of the essentials. Routledge.

PekKanen, R. - Nyblade, B. - Krauss, E. S. (2006): Electoral incentives in mixed-member systems: party, posts, and zombie politicians in Japan. American Political Science Review vol. 100. no. 2. 183-193.

RiCHARD, O. C. - JOHNSON, N. B. (2001): Strategic human resource management effectiveness and firm performance. International Journal of Human Resource Management vol. 12. no. 2. 299-310.

Walliman, N. (2017): Research methods: The basics. London - New York, Routledge.

Data Files used.

Suning Employee Satisfaction SPSS Data File. 